Anis Chaari

Mabrouk Bahloul
Hassen Dammak
Gharbi Nourhene
Noureddine Rekik
Chelly Hedi
Ben Hamida Chokri
Mounir Bouaziz

\section{Guillain-Barré syndrome related to pandemic influenza A (H1N1) infection}

Accepted: 25 March 2010

Published online: 29 April 2010

(C) Copyright jointly held by Springer and ESICM 2010

Dear Editor,

Since April 2009, the world has been experiencing a pandemic

influenza caused by the reasserting virus A (H1N1). Little information about neurological complications induced by this virus is available in the literature. We report the case of a 37-year-old woman who was admitted to our intensive care unit for respiratory distress associated with flaccid tetraplegia. Two weeks ago, she had fever, asthenia, and cough. A nasopharyngeal swab was performed, and reverse-transcription polymerase chain reaction (RT-PCR) confirmed infection with pandemic flu virus A (H1N1). Ten days later, she suffered muscular weakness of the lower limb, then the upper limb. At admission, she had normal consciousness, flaccid tetraplegia with complete areflexia, and symmetric paresthesia of the lower limb. A few hours later, she developed severe dyspnea with impaired coughing, accumulation of airway secretions, nasal voice, swallowing difficulties, and severe hypoxemia $\left(\mathrm{SpO}_{2}\right.$ at $85 \%$ under 101 oxygen/min) requiring mechanical ventilation. During the first 2 days, episodes of bradycardia and hypertension were recorded on hemodynamic monitoring. Diagnosis of Guillain-Barré syndrome was considered and confirmed by electromyography showing reduction in motor conduction velocity and prolonged distal latencies, which were more severe in the lower limb. On analysis of cerebrospinal fluid, there was no albuminocytologic dissociation. Investigations performed in order to identify another triggering factor were negative.

Five consecutive plasma exchanges were performed, and the patient improved progressively. Repeated and prolonged weaning tests were successful, and the patient had a vigorous cough. She was free from mechanical ventilation within 2 weeks, and neither swallowing problems nor dysautonomia abnormalities were reported. The patient was discharged from our intensive care unit within 45 days.

Guillain-Barré syndrome is an acute, immune-mediated polyradiculoneuropathy. In $66 \%$ of patients, history of respiratory or gastrointestinal infection within 6 weeks preceding onset of the disease is found [1]. Some infectious agents are particularly known as triggering factors of Guillain-Barré syndrome [2]. Sivadon-Tardy et al. [3] reported that influenza virus can also induce Guillain-Barré syndrome, but the majority of infections were due to virus A (H3N2), and clinical course was less severe compared with other infectious agents. For our patient, acute respiratory failure and bulbar dysfunction were the main causes leading to intensive care admission. Bulbar dysfunction can be responsible for autonomic instability and aspiration that worsens respiratory distress [4]. Determining the best time for mechanical ventilation is crucial, and up to $25 \%$ of patients with Guillain-Barré syndrome may need mechanical ventilation [1]. Delayed intubation, especially when bulbar dysfunction is considered, may increase the risk of early-onset pneumonia related to aspiration [4]. In adults, plasmapheresis is considered the gold standard for treatment of the most severe cases of GuillainBarré syndrome. In five randomized trials, plasma exchange reduced the need for prolonged ventilation from $27 \%$ to $4 \%$ [2].

To the best of our knowledge, there are no available data concerning clinical severity and prognosis of Guillain-Barré syndrome related to pandemic flu virus A (H1N1). Further studies are needed to clarify the incidence of this complication and its prognostic impact.

Conflict of interest statement None.

\section{References}

1. Cosi V, Versinods M (2006) GuillainBarré syndrome. Neurol Sci 27:S47-S51

2. Hughes RAC, Cornblath DR (2005) Guillain-Barré syndrome. Lancet 366:1653-1666

3. Sivadon-Tardy V, Orlikowski D, Porcher R, Sharshar T, Durand MC, Enouf V, Rozenberg F, Caudie C, Annane D, van der Werf S, Lebon P, Raphaël JC, Gaillard JL, Gault E (2009)

Guillain-Barré syndrome and influenza virus infection. Clin Infect Dis 1:48-56

4. Orlikowski D, Sharshar T, Porcher R, Annane D, Raphael JC, Clair B (2006) Prognosis and risk factors of early onset pneumonia in ventilated patients with Guillain-Barré syndrome. Intensive Care Med 32:1962-1969

A. Chaari ( $)$ - M. Bahloul · H. Dammak · G. Nourhene $\cdot$ N. Rekik · C. Hedi B. H. Chokri · M. Bouaziz Service de réanimation médicale, $\mathrm{CHU}$ Habib Bourguiba, Sfax, Tunisia e-mail: anischaari2004@yahoo.fr 